\title{
The Academic Achievement of Elite Athletes at Australian Schools
}

\author{
Steve Georgakis ${ }^{1}$, John Robert Evans ${ }^{1} \&$ Leanne Warwick ${ }^{1}$ \\ ${ }^{1}$ The University of Sydney, Australia \\ Correspondence: Steve Georgakis, Faculty of Education and Social Work, The University of Sydney, Australia
}

Received: November 27, 2014

Accepted: December 11, 2014 Online Published: December 19, 2014

doi:10.11114/jets.v3i1.616

URL: http://dx.doi.org/10.11114/jets.v3i1.616

\begin{abstract}
While sport and student-athletes have featured in the Australian education system since compulsory schooling, there has been no analysis to date of the link between academic achievement and elite student-athletes. However, this is in stark contrast to the United States of America (US), where student-athletes have been the subject of sustained research and examination. In order to rectify this neglected area of research in the Australian context, this study investigated the Higher School Certificate (HSC) results of 641 Combined High School (CHS) Blues recipients over 11 years from 2001 until 2011, comparing them with the performance of the total general HSC population over the same period. The HSC summary aggregate data for Blues recipients was examined for 15 subjects, plus gender and sport. School Index of Community Socio-Economic Advantage (ICSEA) value also formed part of the analysis. The results demonstrated the student-athletes performed at levels similar to, or better than, their peers. Their performance was notably superior in some subjects such as Personal Development, Health and Physical Education (PDHPE). In particular, female Blues performed at higher levels than male Blues, across the range of subjects. Female Blues also generally outperformed the general HSC population. Analysis of individual Blues sports suggests that swimming produced a disproportionate number of high attainers. The findings suggest that despite their heavy sporting commitments and necessarily demanding training timetables, the sampled elite student-athletes performed at levels equal to, or better than, their peers.
\end{abstract}

\section{Introduction}

Despite their relatively small numerical representation, elite athletes occupy a socially prominent position, and while school sport literature is expanding in Australia, there remain a number of significant issues that have not been dealt with. A dominant issue in the scholastic setting in recent times is that of academic achievement. The introduction in 2008 of high-stakes testing by the way of the National Assessment Program Literacy and Numeracy (NAPLAN) put a sharper focus on academic achievement and key learning areas. Following this, 2010 saw the advent of the Federal Government's My School website, which is to publicise NAPLAN results, providing an average grade comparisons between schools. The My School website and high stakes testing such as NAPLAN has resulted in increased pressure on schools to ensure their students are achieving academic success. Some scholars have noted that subject areas outside the traditional subjects such as English and Maths have been threatened with marginalisation (for impact of high-stakes testing see: Wilson, 2007; Polesel, Dulfer \& Turnbull, 2012). Martin (2010) reported that two years into NAPLAN, physical education and school sport were already being relegated down the curriculum priority list. Apart from the influence of NAPLAN, this is also a timely research due to issues surrounding 'school sport' having come to the forefront in both the public and academic settings in 2012. First, when the draft National Curriculum was released in March 2012, it was noted that:

A notional time allocation of 80 hours per year will be used as a guide by writers as they develop the Australian Curriculum: Health and Physical Education. It is important to note the notional time allocation for Health and Physical Education does not include co-curricular school sport programs. Decisions regarding the time allocation for learning areas in schools remain a jurisdictional responsibility (ACARA, 2012, p.10).

Second, Australian Olympic Committee President John Coates attributed Australia's "poor showing" at the London Olympic Games to the lack of sport in schools (Wilson, 2012). What the numerous examples noted above clearly highlighted, was the lack of research into Australian school sport, and a necessity to instigate further research in this area.

Given the importance of both sport and educational attainment in Australia, this research aims to add to the global field of literature surrounding sporting participation and academic attainment, by investigating the academic achievement of New South Wales (NSW) Combined High Schools (CHS) Sporting Blues recipients ( $n=641$ ), from 2001 until 2011. The commencement date of the research from 2001 coincides with the introduction of the new way of reporting HSC results. 
Analysing data prior to 2001 would have been difficult due to different measurement scales, presenting significant challenges in comparing student results. In the year 2000, NSW students who were in year 11 started the New HSC curriculum, which culminated in the first standards-based, New HSC examinations in 2001 (BOS, 2007, para 1). In addressing these concerns, the New HSC introduced the Band system that gives six clearly defined levels of achievement (Bands 1 - 6), providing performance standards against which student achievement is marked (BOS, 2007, para 7). Therefore it was this change in HSC that dictated that the sample period for this research project would begin from 2001 with the New HSC.

Blues recipients were chosen to be the sporting sample as they are a previously identified group of athletes. Blues are awarded to athletes who win or perform with distinction in an open level at the highest competition (representing CHS), with many past recipients going on to represent Australia at the Olympics. Therefore, those who are awarded a Blue are joining an elite group of athletes (SSU, 2011, pp. 1, 3). Unlike Blues in historic universities such as Oxford and Cambridge (United Kingdom), there are no academic criteria placed on the allocation of Blues, rather they are awarded purely for sporting performance.

\section{Background Information}

An extensive review of literature has shown that the relationship between sport and academic achievement is an area that has been widely researched, particularly in the US (see for examples, Bowen \& Levin, 2003; Comeaux, 2005; Gaston-Gayles \& Hu, 2009; Gaston-Gayles, 2005; Hartmann, 2008). This theme has been of real interest to scholars in the United States (US) because there has been a long tradition of sports scholarships, and the fact that University sport has been commercialized since the 1950s (Eitzen, 2006; Comeaux \& Harrison, 2011). Despite this apparent abundance of research, the literature indicates that the link between academic achievement and sporting achievement (elite athletes) remains somewhat ambiguous and highly contested. For example, early research in the 1970s and early 1980s failed to find a positive association between academic performance and participation in sport (Lueptow \& Kavser, 1973; MacMahon \& Gross, 1987). In comparison, some recent research has shown, at the very least, that the relationship is unclear (Biddle, 1995), with others finding that there are clear, positive correlations between sporting participation and academic performance (Tremblay, Inman \& Willms, 2000; Lipscombe, 2006; Pfeifer \& Cornelissen, 2010).

There have been few studies conducted in Australia that investigate the link between sporting participation and academic achievement. However, of those that have the majority focused on students at the primary, rather than secondary, school level (see Dollman, Boshoff, \& Dodd, 2006; Dwyer, Coonan, Worsley, \& Leitch, 1979). The earliest Australian study conducted by Dwyer et al. (1979) was an intervention study with 519 primary school children (10 year olds) across seven schools. The results showed that despite the experimental groups from each school experiencing a reduction in academic learning time (due to increased time in physical activity), this did not negatively affect academic gains in literacy and numeracy. Dollman et al. (2006) conducted a cross-sectional study with primary school aged students in South Australia, measuring the time spent in physical education classes the previous week. The findings showed that those who spent increased time in physical education did not have reduced levels of academic achievement, despite a reduction in academic learning.

The most recent Australian study by Martin (2010) reviews previous literature on academic achievement and physical activity in an effort to justify the inclusion of physical activity within school curricula. Martin (2010) examines the physiological affects of physical activity on cognitive functioning, as well as health benefits, concluding by making the following recommendation:

Schools can be encouraged to maximise time children spend in physical activity and sport; and reassured that replacing academic time with physical activity and sport will not have a detrimental effect on children's academic success, and may actually support and optimise learning (Martin, 2010, p. 5).

The above studies clearly highlight that in the Australian setting there has been no research that has attempted to develop an in depth understanding of academic achievement of elite athletes. This is surprising, as Australia has always held a strong tradition of sport in the various educational settings.

\section{Methodology}

This study is a secondary data analysis involving the examination of NSW HSC data for the Blues population and the total HSC candidature. Secondary data analyses analyse either quantitative or qualitative data that is already in existence (Trzesniewski, Donnellan \& Lucas, 2011). In order to obtain the required data for this study, the NSW DEC School Sport Unit, who provided access to information regarding the NSW CHS Blues from 2001 to 2011 by enabling access to all their archives. To comply with the ethical use of secondary data and because the HSC data is particularly sensitive, as evidenced by it being protected by NSW legislation, only aggregate data was accessed. The relatively small sample was the main reason this data could only be released in aggregate form to the researcher. Blues HSC 
achievement for each subject was provided only as total numbers in HSC attainment bands over the sample 11-year period. It was not possible to access data for each individual year as this would have represented small numbers (approximately 60 per year), in which individuals were potentially identifiable by sport and gender. With this in mind, the available data for analysis included: Students HSC results aggregate summary data, for each subject, for the identified list of sporting Blues during the period 2001-2011; Students HSC aggregate summary data for the six largest cohort subjects, disaggregated by sport for the five largest cohort groups; School name, used to identify school type and ICSEA value; Student gender; and identification of Blue's recipients who did not complete their HSC and reasons for this.

This is a whole population study of two cohorts (Blues and total HSC). The HSC cohort included during the 11-year period was large. In fact, in the last year analysed for this study (2011), more than 70,000 students sat the exams. Over the 11-year period to 2011, half a million students undertook the NSW HSC. Of these, there were 641 students who were awarded Blues and completed their HSC over this period. This study is a comparative analysis of the Blues and total HSC cohorts. The data are for the total population of these two cohorts for the years 2001-2011. To effectively compare these two groups, two approaches have been used: Graphical and tabular display of the two population cohort's HSC performance; and inferential statistics, in the form of chi-square tests, examining the size of the difference between the two cohorts and reporting the probability of finding those differences by chance.

\section{Results}

\subsection{NSW Blues Information}

Figure 1 (Blues awarded by year) shows the breakdown of number of Blues awarded each year in the sample period (2001-2011). The red line plots the three-period moving average trend line for the Blues awarded 2001-2011, in order to highlight patterns in the number of Blues awarded. From 2001-2008 the average Blues awarded was 62 per year, with the most Blues being awarded in 2007 ( $n=68)$. Notably, there is a significant decline in awards from 2009-2011 (inclusive). In the period 2009-2011, the average Blues awarded was 48 per year, which represents a 23\% drop in averages from the previous period.

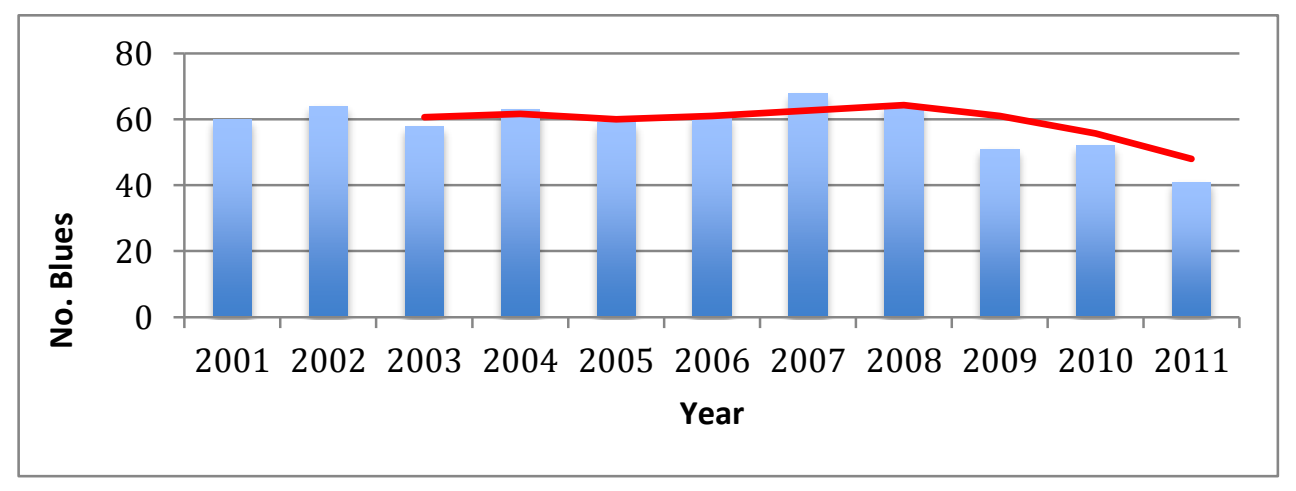

Figure 1. Blues awarded by year, with three-period moving average trend line

It can be clearly noted from the data that $92 \%$ of Blues were awarded to students from co-educational schools. This result in itself is not highly significant as single-sex schools only account for approximately $10 \%$ of NSW public secondary schools. A comparison of sports schools against other high schools found that Westfields Sports High is a clear outlier, with 50 students receiving awards over the 11-year period, giving that school almost $8 \%$ of the total awards. Endeavour Sports High and Kirrawee High School each had 13 students receive Blue awards (2.03\%), closely followed by Illawarra Sports High with 12 Blues (1.87\%). Combined, the seven awarded NSW sports high schools comprise more than $15 \%$ of the total Blues in the sample period. With this in mind, it is interesting to note that six of these sports high school fall significantly below the average ICSEA value (1000), notably Matraville Sports High School, which has an ICSEA value of 866 . Of the top ten schools ranked by ICSEA value, six have been awarded only one or two Blues in the sample period, with Baulkham Hills (ranked 7th) receiving the most Blues (9). Further to this, the results demonstrate that schools under the average ICSEA value (1000) comprise almost $60 \%$ of all awards in the sample period. The gender breakdown elicited significant information relating the distribution of Blues between male and female students. The first theme to emerge was that there were more male than female Blues recipients over the sample period. The breakdown was 348 awards to male students (54.29\%) and 293 awards to females (45.71\%). This disparity is significant, however it could be attributed to the fact that there were more male dominated sports than female dominated sports (such as AFL, rugby league, and rugby union) and these sports are all team sports, meaning more male athletes had the opportunity to receive a Blue award than female athletes. Further to this, only two of the 
sampled years (2002 and 2011) were female athletes awarded more Blues than male athletes, and even then females were only awarded two and one more awards (respectively), than males.

In the sample period 2001-2011, Blues were awarded to athletes from 27 different sports. The five most awarded sports were swimming $(n=49)$, football $(n=42)$, touch $(n=41)$, athletics $(n=40)$, and cricket $(n=40)$, and account for one third of the awards over the sample period. Additionally, the results show that seven out of the top 10 Blue awarded sports are team sports, with only swimming, athletics, and rowing having a combination of individual and team events. Lastly, it should be noted that the results show the majority of Blues awarded sports are those that can be played with minimal equipment, for example swimming, football, touch, and athletics. While some athletic events do require specialised equipment (for example high jump, or throwing events such as discus and javelin), most schools are in possession of a sufficient number of these equipment, as athletics carnivals are held annually in all schools, therefore it is necessary for schools to possess such equipment to enable participation.

\subsection{Graphical Analysis}

The previous section provided a descriptive analysis of the sample group of Blues recipients; highlighting differences in sports, gender, and school type. Within this section, the six most popular subjects studied by Blues recipients are analysed. These six subjects are PDHPE, Mathematics, General Mathematics, Standard English, Advanced English, and Biology. As a base for comparison, the average proportion of students in the general HSC population obtaining a result in each band was found over the 11-year sample period. This was achieved by averaging the proportion in each band, for each subject over 11 years.

Of the 15 subjects for which these averages were obtained, six were identified as having a large number of Blues over the sample period (outlined above). The issue of data confidentiality meant that analysis of subjects with fewer Blues enrolments was not feasible. For each of the six subjects the aggregated HSC data was entered into SPSS along with the results of the Blues recipients in the same subjects, to generate the following figures. For each subject, the proportion of students in each band is shown for the total HSC population and Blues recipients. Blues HSC results were also examined by gender, as well as the six most awarded sports (Athletics, Cricket, Football, Swimming, and Touch). The six identified subjects have been analysed below in alphabetical order.

\subsubsection{Biology Analysis.}

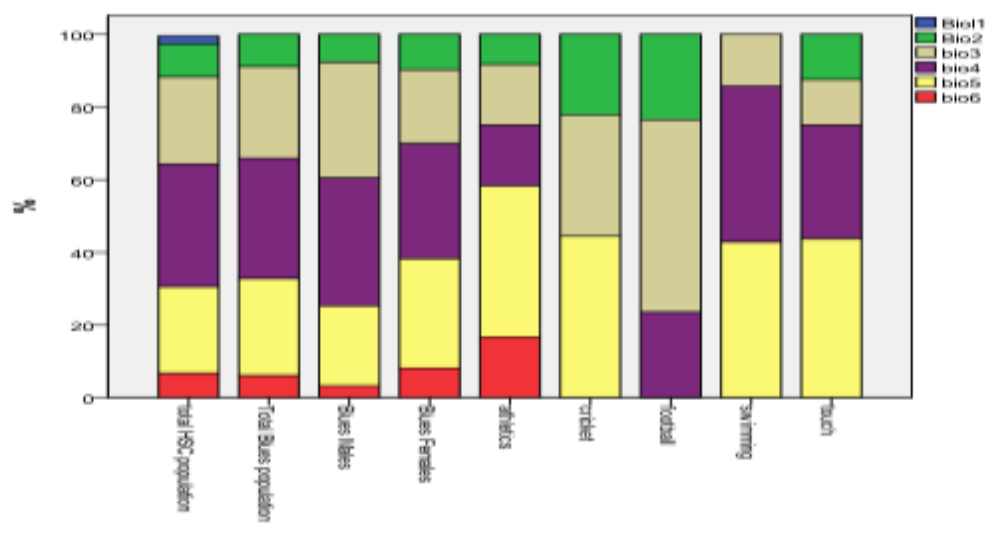

Figure 2. Biology Analysis

The figure illustrates that results between total HSC population and total Blues population are, overall, comparable, with the main difference highlighted in the lack of Band 1 received by Blues. Analysis of the sporting subsets demonstrates that athletics was the highest achieving sport, with almost three out of five students in the cohort achieving Bands 5 and 6. This is significantly higher than the total HSC population, who received only $30 \%$ Band 5 and 6. Again, female Blues recipients outperformed male Blues, with females receiving $38 \%$ Band 5 or 6 , compared to $25 \%$ for males. Female Blues achieved slightly higher than the total HSC population, which had $30 \%$ Bands 5 and 6 . This detailed analysis shows that the Blues recipients perform marginally better than the general HSC population, with $66 \%$ receiving a Band 4 or higher (compared with $64 \%$ for the general HSC populatuon). In particular, swimmers, athletes and Females achieved substantially higher results than the general population.

\subsubsection{English Advanced Analysis}




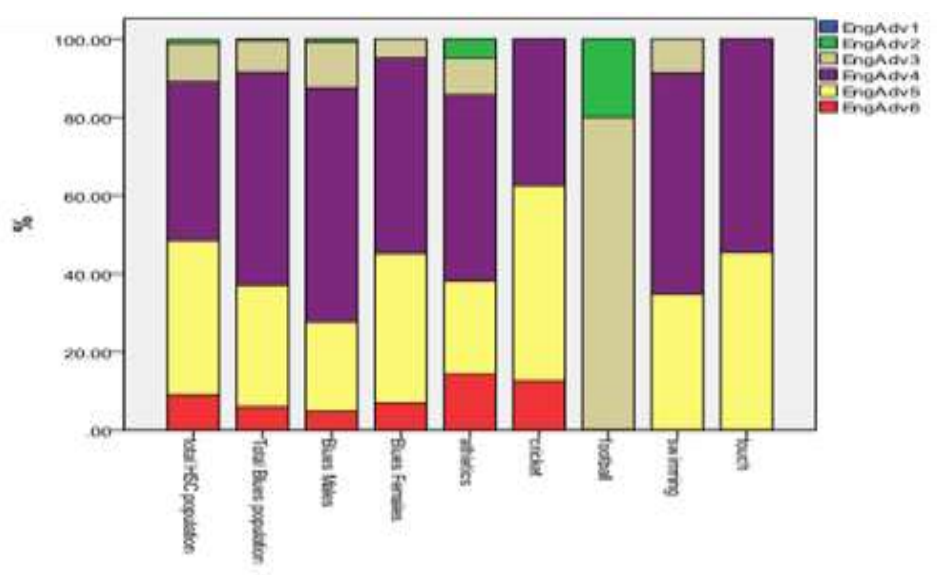

Figure 3. Advanced English Analysis

This figure displays that overall, the Blues population received less Bands 5 and 6 (37\%) than the general HSC population (slightly less than half). However, female Blues performed comparably to the total HSC population, with $45 \%$ achieving a Band 5 or 6 , and the cricketers outperformed the total HSC population, receiving over $60 \%$ Bands 5 and 6. Of the sporting groups, Athletics produced the next largest percentage of high achievers, with almost one quarter achieving Band 6.

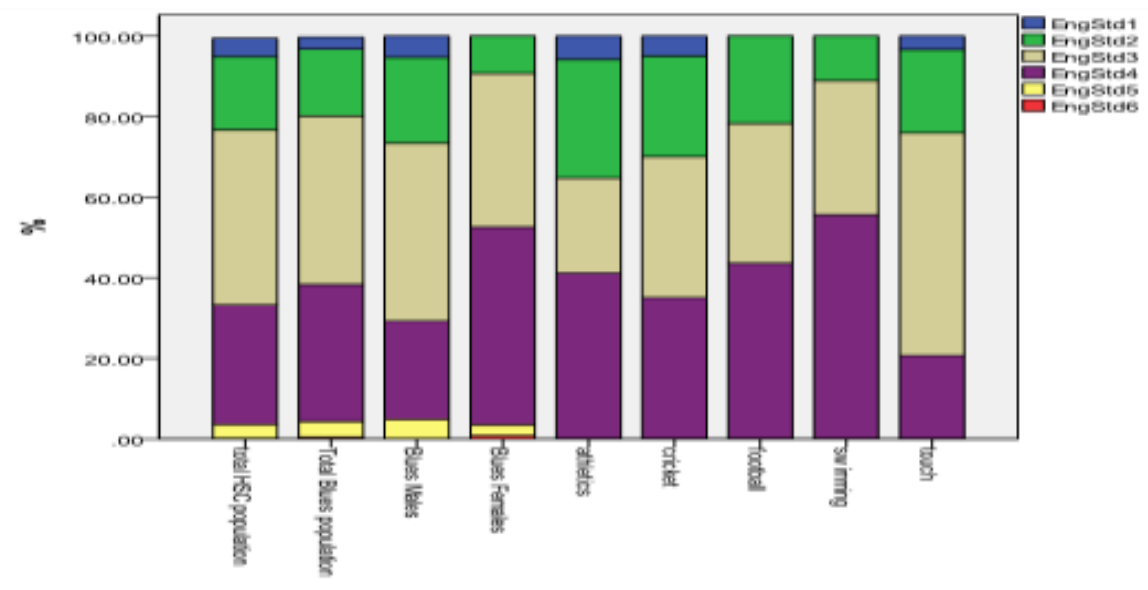

\subsubsection{English Standard Analysis}

Figure 4. English Standard Analysis

Standard English is a unit in which very few enrolled students received a Band 5 or a Band 6. Of the six subjects analysed, it is clear that Standard English produced the greatest number of low achievers (Bands 1 and 2). However, the graph demonstrates that the majority of students received either a Band 3 or 4 . The major trend in this subject is the female Blues and swimmers clearly outperformed the total HSC population with female Blues and swimmers both receiving substantially more Bands 4 (50\% and 55\% respectively) than the total HSC population (30\%). It should be noted that the gender breakdown for swimmers is roughly 50-50. The excellent performance of female Blues recipients and swimmers is further reflected with their substantially lower proportions of Bands 1 and 2 achievers (approximately $10 \%)$.

\subsubsection{General Mathematics Analysis}




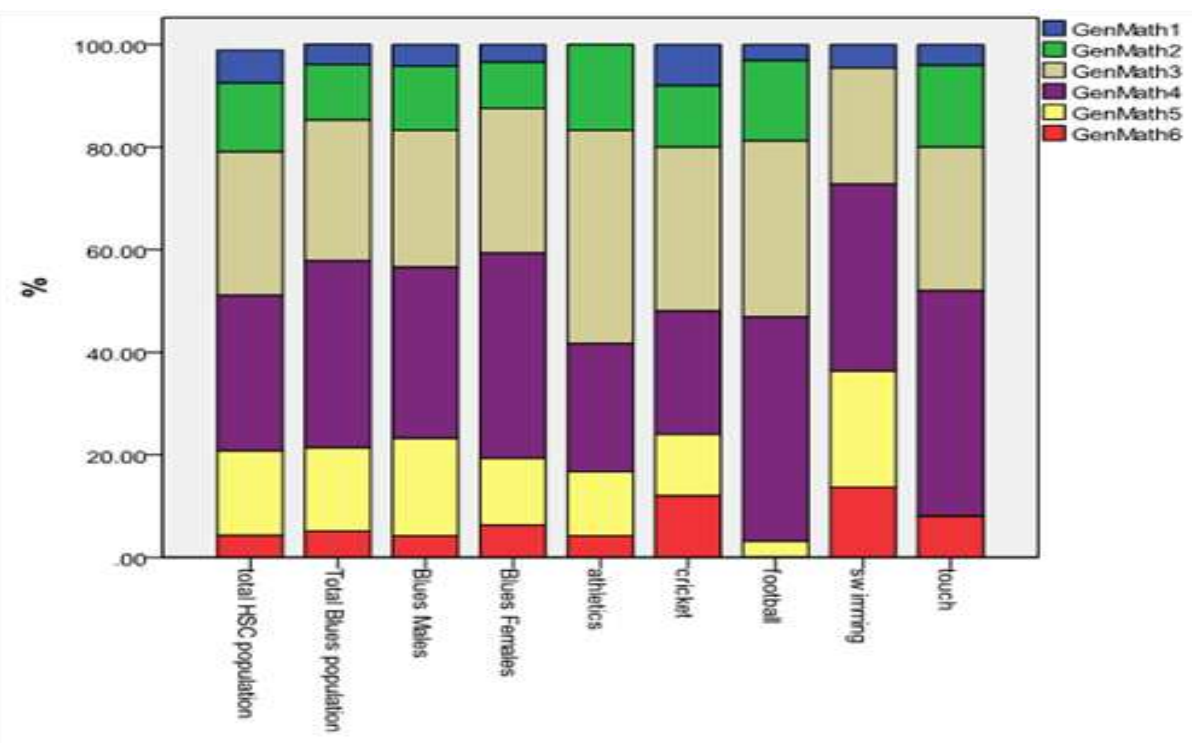

Figure 5. General Maths Analysis

The graph demonstrates that total Blues recipients in General Mathematics attained more Bands 4-6 (58\%) than the general HSC population (51\%). Additionally, the male and female Blues subgroups achieved more Bands 4 and higher than the total HSC population. Furthermore, at the lower end of the scale, Blues recipients received less Bands 1 and 2 (15\%) than the general HSC population (20\%). A gender comparison illustrates that male Blues slightly outperformed female Blues and the total Blues population, with a greater percentage of Band 5 and 6 attainment. Swimmers performed particularly well, with slightly more than $70 \%$ receiving a Band 4 or above and $36 \%$ receiving a Band 5 or higher (compared with $20 \%$ of the total HSC population), with only $5 \%$ receiving a Band 1 or 2.

4.2.5 Mathematics Analysis

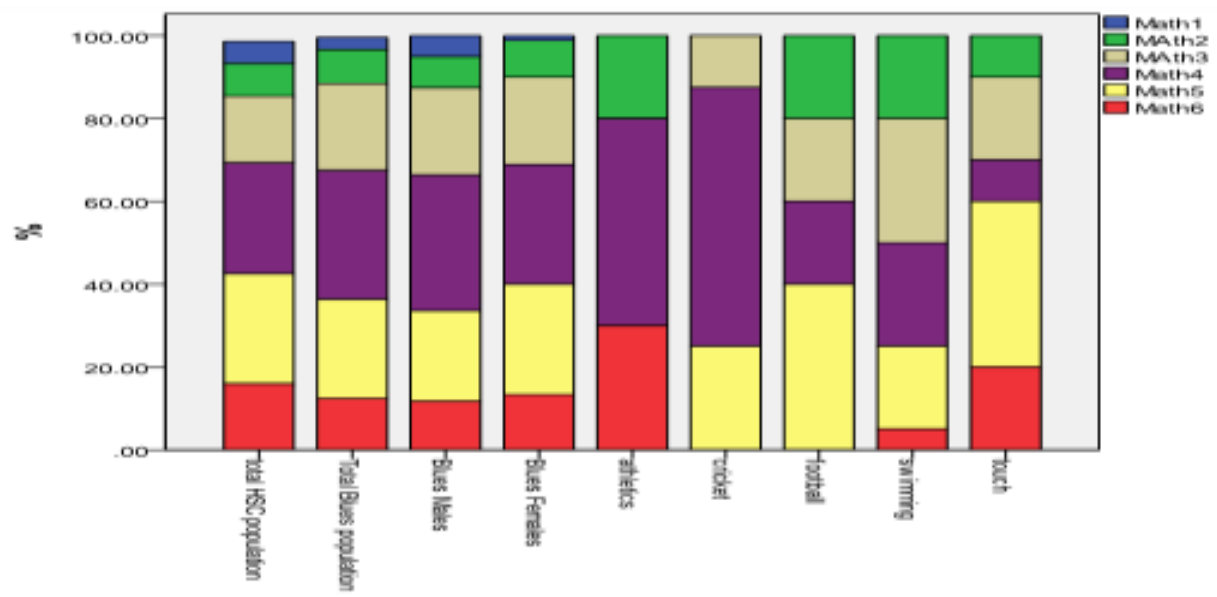

Figure 6. Maths Analysis

For Mathematics, Blues recipients received comparable numbers of Bands 4, 5 and 6 to the total HSC population, which was approximately 70\%. This number also applied for male and female Blues subsets. At the lower end of the spectrum, Blues recipients received marginally fewer Bands 1 and 2 than the general HSC population. The figure clearly shows that Cricketer's received more Band 4 than any other Blues subset, and that $60 \%$ of Touch players were in either Band 5 or 6. No sporting group appeared to receive any Band 1, however these patterns should be regarded with caution due to the small sample sizes in individual sporting groups.

\subsubsection{PDHPE Analysis}




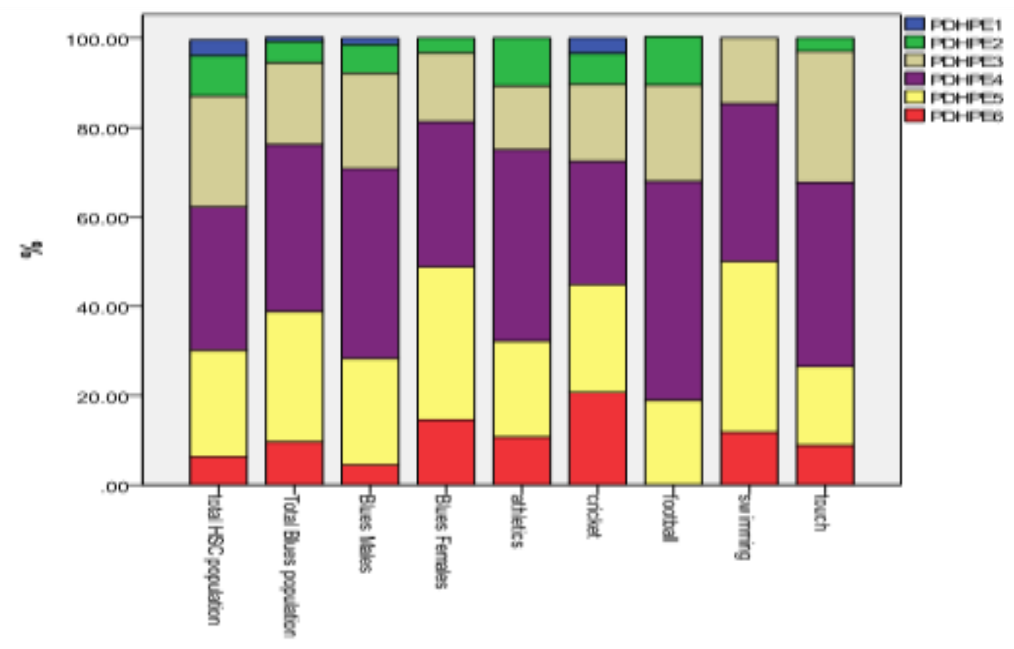

Figure 7. PDHPE Analysis

The figure demonstrates that while $62 \%$ of the total HSC population achieved a Band 4 and above, the corresponding statistic for all Blues recipients was $75 \%$. This achievement is particularly pronounced in female Blues recipients, with approximately $80 \%$ receiving a Band 4, 5 or 6, and similar results for Swimmers who were also well above the general HSC population. At the lower achievement levels, $13 \%$ of the general HSC population received Band 1 or 2, which is in stark contrast to the $6 \%$ of Blues recipients who received a Band 1 or 2 . Remarkably, no Swimmers achieved less than a Band 3 result. Cricket, Athletics and Football received similar percentages of Bands 1 and 2 (10\%), however Cricket was the only sport in which Band 1 was attained. It is apparent from the graph that the swimmers were the best performing subset of Blues. This analysis highlights that all Blue subsets (gender and sports) out performed the general population in PDHPE, with more high achievers and proportionately fewer low achievers.

\subsection{Statistical Analysis Using Chi-Squared Testing}

The descriptive analysis (above) highlighted a number of differences between the general HSC population and the Blues recipients. To determine the statistical significance of these differences, Chi-square goodness-of-fit tests have been performed. The aim was to determine if the distribution of Blues recipients results conforms to that of the general HSC population. Bands have been aggregated so that Bands 1-3 are grouped together, representing the lower achievers and Bands 4-6 representing the higher achievers. This was done in order to avoid the issue of small expected counts and to give a clearer overview of the broad differences between Blues recipients and the general HSC population. Tables 1-6 (below) represent the results of the Chi-squared analysis. The first column of the table ("Comparison across all bands") present the Chi-Squared results for individual bands, however this was found to be unreliable due to small counts. The second column ("Comparing high V low") presents the test results once applied to the grouped data (Bands 1-3 representing low, and Bands $4-6$ representing high). This data was used for the analysis as it produced results that were highly reliable and valid. Highly significant differences ( $p$-values less than 0.05) were found between Blues and the total HSC population in three of the subjects (Standard English, General Maths, PDHPE), with the remaining three subjects producing insignificant results (Advanced English, Mathematics, Biology). Insignificant results indicate that there is little or no difference in the academic achievement of blues compared with the general HSC population. Chi-squared analysis of PDHPE produced a p-value of 0.00 , indicating a very significant difference between the attainment of Blues and the HSC population, and that this difference is highly unlikely to have occurred by chance. For ease of reference, highly significant results have been highlighted in red, whilst insignificant results have been highlighted blue. 
Table 1. Chi-squared test Biology

\begin{tabular}{|c|c|c|c|c|c|c|c|c|c|}
\hline & \multicolumn{2}{|c|}{$\begin{array}{l}\text { COMPARISON } \\
\text { BANDS }\end{array}$} & \multicolumn{4}{|c|}{ ACROSS ALL } & \multicolumn{3}{|c|}{$\begin{array}{l}\text { COMPARISON } \\
\text { LOW }\end{array}$} \\
\hline Biology & $\mathbf{1}$ & 2 & 3 & 4 & 5 & 6 & 1 to 3 & 4 to 6 & \multirow{8}{*}{$\begin{array}{c}\text { Total }= \\
\mathbf{2 1 4}\end{array}$} \\
\hline HSC percent & 0.02 & 0.09 & 0.24 & 0.34 & 0.24 & 0.07 & 0.35 & 0.64 & \\
\hline Expected number & 6.86 & 27.65 & 73.77 & 102.88 & 72.90 & 20.61 & 75.72 & 137.35 & \\
\hline Observed Blues & $\mathbf{0}$ & 19 & 54 & 71 & 57 & 13 & 73 & 141 & \\
\hline difference & 6.86 & 8.65 & 19.77 & 31.88 & 15.90 & 7.61 & 2.72 & -3.65 & \\
\hline difference ${ }^{\wedge} 2$ & 47.02 & 74.80 & 390.89 & 1016.33 & 252.91 & 57.96 & 7.41 & 13.33 & \\
\hline difference ${ }^{\wedge} 2 /$ expected & 6.86 & 2.71 & 5.30 & 9.88 & 3.47 & 2.81 & 0.10 & 0.10 & \\
\hline & \multicolumn{2}{|r|}{$\begin{array}{r}\text { Chi-sq. } \\
31.02\end{array}$} & $\begin{array}{r}\mathrm{p} \text {-value } \\
0.00\end{array}$ & \multicolumn{3}{|c|}{$\begin{array}{l}\text { Unreliable as expected cell counts } \\
\text { for band } 1 \text { is }<5\end{array}$} & $\begin{array}{l}\text { Chi-sq. } \\
0.19\end{array}$ & $\begin{array}{r}\mathrm{p} \text {-value } \\
\mathbf{0 . 6 6}\end{array}$ & \\
\hline
\end{tabular}

Table 2. Chi-squared test English Advanced

\begin{tabular}{|c|c|c|c|c|c|c|c|c|c|}
\hline & \multicolumn{2}{|c|}{$\begin{array}{l}\text { COMPARISON } \\
\text { BANDS } \\
\end{array}$} & \multicolumn{4}{|c|}{ ACROSS ALL } & \multicolumn{3}{|c|}{$\begin{array}{l}\text { COMPARING } \\
\text { LOW }\end{array}$} \\
\hline English Advanced & 1 & 2 & 3 & 4 & 5 & 6 & 1 to 3 & 4 to 6 & \multirow{8}{*}{$\begin{array}{c}\text { Total }= \\
\mathbf{2 7 3}\end{array}$} \\
\hline HSC percent & 0.00 & 0.01 & 0.10 & 0.41 & 0.40 & 0.09 & 0.11 & 0.89 & \\
\hline Expected number & 0.26 & 2.60 & 30.05 & 124.24 & 121.09 & 27.32 & 29.36 & 243.25 & \\
\hline Observed Blues & $\mathbf{0}$ & 1 & 22 & 149 & 85 & 16 & 23 & 250 & \\
\hline difference & 0.26 & 1.60 & 8.05 & -24.76 & 36.09 & 11.32 & 6.36 & -6.75 & \\
\hline difference ${ }^{\wedge} 2$ & 0.07 & 2.55 & 64.88 & 612.98 & 1302.67 & 128.08 & 40.51 & 45.59 & \\
\hline \multirow[t]{2}{*}{ difference ${ }^{\wedge} 2 /$ expected } & 0.26 & 0.98 & 2.16 & 4.93 & 10.76 & 4.69 & 1.38 & 0.19 & \\
\hline & & $\begin{array}{l}\text { hi-sq. } \\
23.78\end{array}$ & $\begin{array}{l}\text { value } \\
\qquad 0.00\end{array}$ & $\begin{array}{l}\text { Unre } \\
\text { counts }\end{array}$ & $\begin{array}{l}\text { able as ex } \\
\text { r bands } 1\end{array}$ & $\begin{array}{l}1 \text { cell } \\
\text { are }<5\end{array}$ & $\begin{array}{r}\text { Chi-sq. } \\
1.57\end{array}$ & $\begin{array}{r}\text { p-value } \\
\mathbf{0 . 2 1}\end{array}$ & \\
\hline
\end{tabular}

Table 3. Chi-squared test English Standard

Insignificant difference

\begin{tabular}{|c|c|c|c|c|c|c|c|c|c|}
\hline \multirow[b]{2}{*}{ English Standard } & \multicolumn{2}{|c|}{$\begin{array}{l}\text { COMPARISON } \\
\text { BANDS }\end{array}$} & \multicolumn{4}{|c|}{ ACROSS ALL } & \multicolumn{3}{|c|}{ COMPARING LOW V HIGH } \\
\hline & 1 & 2 & 3 & 4 & 5 & 6 & 1 to 3 & 4 to 6 & \multirow{8}{*}{$\begin{array}{c}\text { Total }= \\
\mathbf{3 0 6}\end{array}$} \\
\hline HSC percent & 0.05 & 0.18 & 0.43 & 0.30 & 0.03 & 0.00 & 0.66 & 0.33 & \\
\hline Expected number & 14.30 & 55.55 & 132.88 & 90.90 & 10.57 & 0.24 & 203.18 & 99.45 & \\
\hline Observed Blues & 10 & 51 & 128 & 104 & 12 & 1 & 189 & 117 & \\
\hline difference & 4.30 & 4.55 & 4.88 & -13.10 & -1.43 & -0.76 & 14.18 & -17.55 & \\
\hline difference $^{\wedge} 2$ & 18.45 & 20.73 & 23.81 & 171.50 & 2.06 & 0.57 & 201.19 & 308.00 & \\
\hline difference 2 /expected & 1.29 & 0.37 & 0.18 & 1.89 & 0.19 & 2.37 & 0.99 & 3.10 & \\
\hline & \multirow{2}{*}{\multicolumn{2}{|c|}{$\begin{array}{r}\text { Chi-sq. } \\
6.30 \\
\end{array}$}} & $\begin{array}{r}\mathrm{p} \text {-value } \\
0.28\end{array}$ & \multicolumn{3}{|c|}{$\begin{array}{c}\text { Unreliable as expected cell count } \\
\text { for band } 6 \text { is }<5\end{array}$} & \multicolumn{2}{|c|}{$\begin{array}{rr}\text { Chi-sq. } & \text { p-value } \\
4.09 & \mathbf{0 . 0 4}\end{array}$} & \\
\hline & & & & & & & \multicolumn{3}{|c|}{$\begin{array}{l}\text { Significant difference - Blues } \\
\text { doing better }\end{array}$} \\
\hline
\end{tabular}


Table 4. Chi-squared test General Maths

\begin{tabular}{|c|c|c|c|c|c|c|c|c|c|}
\hline \multirow[b]{2}{*}{ General Maths } & \multicolumn{6}{|c|}{$\begin{array}{l}\text { COMPARISON ACROSS ALL } \\
\text { BANDS }\end{array}$} & \multicolumn{3}{|c|}{$\begin{array}{l}\text { COMPARING HIGH V } \\
\text { LOW }\end{array}$} \\
\hline & 1 & 2 & 3 & 4 & 5 & 6 & 1 to 3 & 4 to 6 & \multirow{8}{*}{$\begin{array}{c}\text { Total = } \\
\mathbf{3 1 3}\end{array}$} \\
\hline HSC percent & 0.06 & 0.13 & 0.28 & 0.30 & 0.16 & 0.04 & 0.48 & 0.51 & \\
\hline Expected number & 19.58 & 41.25 & 85.70 & 92.84 & 50.45 & 12.97 & 149.88 & 159.83 & \\
\hline Observed Blues & 12 & 34 & 86 & 114 & 51 & 16 & 132 & 181 & \\
\hline difference & 7.58 & 7.25 & -0.30 & -21.16 & -0.55 & -3.03 & 17.88 & -21.17 & \\
\hline difference $^{\wedge} 2$ & 57.43 & 52.59 & 0.09 & 447.73 & 0.30 & 9.20 & 319.65 & 447.96 & \\
\hline \multirow[t]{3}{*}{ difference ${ }^{\wedge} 2 /$ expected } & 2.93 & 1.27 & 0.00 & 4.82 & 0.01 & 0.71 & 2.13 & 2.80 & \\
\hline & & $\begin{array}{r}\text { Chi-sq. } \\
9.75\end{array}$ & $\begin{array}{l}\text { value } \\
\mathbf{0 . 0 8}\end{array}$ & Insign & cant dif & & $\begin{array}{r}\text { Chi-sq. } \\
4.94\end{array}$ & $\begin{array}{r}\text { p-value } \\
\mathbf{0 . 0 3}\end{array}$ & \\
\hline & & & & & & & \multicolumn{3}{|c|}{$\begin{array}{l}\text { Significant difference - } \\
\text { Blues doing better }\end{array}$} \\
\hline
\end{tabular}

Table 5. Chi-squared test Mathematics

\begin{tabular}{|c|c|c|c|c|c|c|c|c|c|}
\hline & \multicolumn{6}{|c|}{ BANDS } & \multicolumn{3}{|c|}{ HIGH V } \\
\hline Mathematics & 1 & 2 & 3 & 4 & 5 & 6 & 1 to 3 & 4 to 6 & \multirow{8}{*}{$\begin{array}{c}\text { Total }= \\
\mathbf{2 0 9}\end{array}$} \\
\hline HSC percent & 0.05 & 0.08 & 0.16 & 0.27 & 0.27 & 0.16 & 0.29 & 0.69 & \\
\hline Expected number & 16.40 & 24.10 & 49.38 & 81.85 & 81.39 & 48.76 & 61.39 & 144.80 & \\
\hline Observed Blues & 7 & 17 & 44 & 65 & 50 & 26 & 68 & 141 & \\
\hline difference & 9.40 & 7.10 & 5.38 & 16.85 & 31.39 & 22.76 & -6.61 & 3.80 & \\
\hline difference $^{\wedge} 2$ & 88.29 & 50.47 & 28.97 & 283.81 & 985.18 & 518.13 & 43.68 & 14.40 & \\
\hline difference $\mathrm{e}^{\wedge} 2 /$ expected & 5.38 & 2.09 & 0.59 & 3.47 & 12.10 & 10.63 & 0.71 & 0.10 & \\
\hline & \multicolumn{6}{|c|}{$\begin{array}{rr}\text { Chi-sq. } & \text { p-value } \\
34.26 & \mathbf{0 . 0 0}\end{array}$} & $\begin{array}{r}\text { Chi-sq. } \\
0.81\end{array}$ & $\begin{array}{r}\text { p-value } \\
\mathbf{0 . 3 7}\end{array}$ & \\
\hline & & & & & & & \multicolumn{3}{|c|}{ Insignificant difference } \\
\hline
\end{tabular}

Table 6. Chi-squared test PDHPE

\begin{tabular}{|c|c|c|c|c|c|c|c|c|c|}
\hline \multirow[b]{2}{*}{ PDHPE } & \multicolumn{6}{|c|}{$\begin{array}{l}\text { COMPARISON ACROSS ALL } \\
\text { BANDS }\end{array}$} & \multicolumn{3}{|c|}{$\begin{array}{l}\text { COMPARING HIGH V } \\
\text { LOW }\end{array}$} \\
\hline & 1 & 2 & 3 & 4 & 5 & 6 & 1 to 3 & 4 to 6 & \multirow{8}{*}{$\begin{array}{c}\text { Total }= \\
\mathbf{4 1 5}\end{array}$} \\
\hline HSC percent & 0.04 & 0.09 & 0.25 & 0.32 & 0.24 & 0.06 & 0.37 & 0.62 & \\
\hline Expected number & 10.95 & 27.54 & 75.89 & 98.41 & 72.68 & 19.34 & 155.13 & 258.25 & \\
\hline Observed Blues & 3 & 20 & 76 & 155 & 121 & 40 & 99 & 316 & \\
\hline difference & 7.95 & 7.54 & -0.11 & -56.59 & -48.33 & -20.66 & 56.13 & -57.75 & \\
\hline difference $^{\wedge} 2$ & 63.28 & 56.85 & 0.01 & 3202.47 & 2335.31 & 426.87 & 3150.24 & 3334.54 & \\
\hline \multirow[t]{2}{*}{ difference $\mathrm{e}^{\wedge} 2 /$ expected } & 5.78 & 2.06 & 0.00 & 32.54 & 32.13 & 22.07 & 20.31 & 12.91 & \\
\hline & & $\begin{array}{r}\text { Chi-sq. } \\
94.59\end{array}$ & $\begin{array}{r}\text { p-value } \\
\mathbf{0 . 0 0}\end{array}$ & Significa & $t$ difference & & $\begin{array}{l}\text { Chi-sq. } \\
33.22\end{array}$ & $\begin{array}{r}\text { p-value } \\
\mathbf{0 . 0 0}\end{array}$ & \\
\hline
\end{tabular}




\section{Discussion}

In order to ascertain whether or not there was a difference in academic achievement between Blues recipients and the general HSC population, this research considered graphical comparisons and statistical tests. The statistical tests were based around the null hypothesis that there was no difference in the results of Blues and the general HSC population. This hypothesis was rejected for both Standard English and General maths, with the chi-squared goodness-of-fit tests demonstrating that there was a significant difference. Presence of a significant difference indicates that the proportion of high achievers and lower achievers was considerably different. This significance was even more pronounced in the results of the PDHPE Chi-squared test, strongly rejecting the null hypothesis and thereby proving that the Blues recipients significantly outperformed the general HSC population. The graphical representation for Advanced English demonstrates a seemingly large discrepancy between the general HSC population and Blues at the higher end (Bands 4-6), with the general population appearing to have outperformed the Blues. However, the Chi-squared test indicated that, statistically, this difference was not in fact highly significant.

An analysis of the composition of the Blues sample also revealed several remarkable themes, including that highlighted by the three period average trend line, which revealed a significant decline in awards from 2008-2011.

A general analysis across all six subjects determined that the total Blues population attained a higher percentage of Bands 4-6 than the general population in all subjects excepting Mathematics. Furthermore, the female cohort of Blues outperformed the general population considerably by achieving more Bands 4-6 in all six subjects. Conversely, the male Blues achieved more Bands 4-6 in only two of the six subjects (PDHPE and General Maths). Additionally, it is clear overall that female Blues outperformed all other Blues cohorts, receiving with no Band 1 attainers except in Mathematics and General Mathematics.

Analysis of Bands 1 and 2 established that again, the total Blues population outperformed the general HSC population, receiving fewer of these Bands in all six subjects. Similarly, female Blues also attained fewer Bands 1 and 2 than the general population in all six subjects, however male Blues received more Bands 1 and 2 in two of the six subjects (Advanced English and Standard English), although this difference was only marginal for Advanced English. A further clearly discernible pattern was that in five of the six subjects, there was a substantial disparity between high achievers (Bands 4- 6) and low achievers (Bands 1 - 2) across all cohorts. However this was not evident in Advanced English, where the graphical representation displayed students either achieved Bands $4-6$ or Bands $1-2$. There was almost no middle ground (Band 3) for this subject, indicating that students enrolled in this subject either perform very well, or very poorly. Football was the only exception for this pattern in Advanced English, with 80\% Band 3 achievement, however a small sample for this sport is likely to have caused this anomaly. In each of the three statistically significant subjects (PDHPE, General Mathematics, Standard English), no fewer than five of the eight Blues cohorts achieved a higher percentage of Bands $4-6$ than the general HSC population.

Whilst the statistical significance does not give any indication about the size of the effect, it can be assessed through the graphical analysis. The graphical representations demonstrated that in many cases, there were substantial differences between the Blues cohort and the general HSC population. Particularly for PDHPE there was graphical evidence of a large difference between Blues recipients and the general HSC cohort. More Blues achieved Bands 5 and 6 in PDHPE (39\%), compared with the general HSC population (30\%). This difference in performance was also supported by the Chi-squared test result. In Advanced English the statistical test found that there were more Blues recipients achieving Bands 4-6 than for the general HSC cohort. Graphical analysis of Advanced English indicates that while this is true, there are less Blues achieving at the higher levels with only around 35\% achieving a Band 5 and 6, compared with almost half of the general HSC population.

\section{Implications}

The results of this study raise several highly significant educational issues that may have extensive implications in the schooling context. The issue raised is that this research has rejected the 'zero-sum' theory that indisputably underpinned much of the extensive literature to come out of the US (see Miller, Melnick, Barnes, Farrell, \& Sabo, 2005; Hauser \& Lueptow, 1978; Coleman, 1961). Zero-sum theorists subscribe to the belief that students who dedicate time to sport and physical activity, thereby reducing time spent in academic pursuits, inevitably demonstrate lower scholastic ability than non-athletes. However, sport is not the only pursuit in which adolescents partake. It is commonly accepted that a significant percentage of students undertake part-time work whilst still attending school (see ABS, 2012). The NSW Office of Communities in 2010, estimated that of the students aged 15-17 years, 28.0\% were also engaged in part time work, with this figure increasing to 32.5\% as children reached 17 years of age (NSW Office of Communities, 2011).

These figures are a clear indication that many students spend substantial amounts of time partaking in activities beyond schoolwork. Likewise, the elite athletes sampled for this study necessarily spend a large percentage of their time training for their sport, with many missing days to represent their school at school-related sporting commitments (such 
as inter-school, zone, state, national and international competitions). Further to this, most of the Blues would most likely be involved in community sport which would involve another set of commitments. Due to the lack of research into Australia school sport and elite athletes, there is no published, statistical data on the time commitments of elite school-aged athletes. At this stage there is only anecdotal evidence of the time demands placed on student-athletes. The results of this research have therefore discredited the 'zero-sum' argument, finding that students who fulfil the time demands required to become an elite athlete, are still able to attain academic standards higher than, or equal to, non-athletes. The results of this research reflect the findings of Marsh (1993), who reported, "participation in sport apparently adds to-not detracts from-time, energy, and commitment to academic pursuits" (p.35).

The second educational issue raised by the findings is that the results oppose the 'crowded curriculum' argument that has arisen in the wake of the introduction of NAPLAN testing and publication of results via the MySchool website. The NSW Auditor-General's performance audit of physical activity in government primary schools (2012) found the 'crowded curriculum' argument was the major justification from schools for not providing the required hours of sport and physical activity, yet the results of the present study are consistent with previous findings that reducing time in physical activity will not improve results in academic areas such as literacy and numeracy (see Trudeau \& Shephard 2010, 2008; Coet et al., 2006).

A third significant finding was that three in five Blues recipients came from schools with an ICSEA value below the average. Despite this, the results of this research have demonstrated that the Blues sample still attained academic results higher than the total HSC population in several subjects. This is important to note as Miller and Voon (2011) report that while prior academic achievement is one of, if not the strongest, predictor of academic performance, socioeconomic background is also a very strong predictor of student outcomes (p. 369). In relating this to school ICSEA values as an indicator of student performance, Miller and Voon (2011) found each 100-point increase in ICSEA is typically correlated with approximately 30 extra points in most NAPLAN results (p.381). That is, the higher the schools ICSEA value, the higher their students results are likely to be. The results of this study have proven to be the exception to this, highlighting that students who not only operate under substantial time constraints, but who are also from low socio-economic areas, are able to achieve high academic standards.

The fourth and most pertinent issue raised by this research is to do with negative perceptions of student-athletes. The US literature has shown the 'dumb-jock' stereotype pervades educational institutions as well as infiltrating general perceptions of the wider community, implying that student-athletes are unable or unprepared to attain high academic standards (Leach \& Conners, 1984, cited in Simons, Bosworth, Fujita, \& Jensen, 2007, p. 252; Pierce, 2007, p. 801). This stereotype has clearly ben debunked by the this body of findings, which demonstrated that athletes in the Australian secondary school setting at least, are not 'dumb jocks'. From a sample of 641 elite student-athletes, it has been proven that not only have they attained academic standards similar to the general HSC population, in many cases the athletes have outperformed the general population, achieving higher percentages of Bands $4-6$ and lower percentages of Bands 1 - 2 .

\section{Conclusion}

The data analysis clearly demonstrated the difference between the results of the Blues and the general population, across three subjects (PDHPE, Standard English and General Maths), was not related to chance but was in fact statistically significant. Of these three subjects, the greatest distinction was evident in PDHPE, with all Blues subsets demonstrating superior attainment by substantially outperforming the general HSC population at both ends of the scale, producing more Bands 4-6 and fewer Bands 1 and 2. The remaining three subjects (Advanced English, Mathematics and Biology) yielded results that Chi-squared testing determined statistically insignificant (that is, Blues performance was comparable to the general HSC), although it was evident from the graphical data that in Advanced English, the general HSC population outperformed the Blues. Further analysis revealed that whilst female Blues represented less than half of the total Blues population, they were the best performing subset, producing results that were superior to male Blues across four subjects, and performing comparably to males across the remaining two (Standard English and General Mathematics). When compared with the general HSC population, female Blues achieved more Bands 5 and 6 in Biology and PDHPE, with their high-end attainment (Bands 5 and 6) on parity with the general population across the remaining subjects. Analysis of individual Blues sports, suggests that Swimming produced a disproportionate number of high attainers (Bands 5 and 6) across all subjects. A final key finding was that Blues predominantly came from schools that had a lower ICSEA value than the average.

\section{Practical implications}

The timing of the study coincided with great debate that raged in both the media and academic circles regarding the role of school sport. Controversially, school sport is to be axed from the National Curriculum; to some the lack of a viable school sport programs was responsible for the lack of medals at the London Olympics; already, primary schools are not 
delivering enough physical education or school sport (Wilson, 2012; Achterstraat, 2012). What these debates clearly highlight is the lack of empirical research linking sport to other contemporary educational issues such as the introduction of high stakes testing. Literature discussing sport and education in places such as the US has existed for decades and as such it is surprising that a subject that has taken up such a large slice of the curriculum in Australia has been so little analysed. In the era of high stakes testing in the Australian educational landscape, subjects outside the narrow confines of English and Maths justify their existence because of their perceived learning outcomes. Research into the Arts has produced significant literature supporting the link between those subjects and educational achievement (Ewing, 2010). In contrast, researchers in sport and other movement subjects are yet to address this controversial issue.

\section{References}

Australian Curriculum, Assessment and Reporting Authority. (2012). Fact sheet: about NAPLAN. Retrieved July 17, 2012, from http://www.acara.edu.au/verve/_resources/About_NAPLAN.pdf

Australian Curriculum, Assessment and Reporting Authority. (2012). Draft shape of the curriculum: Health and Physical Education. Retireved June 3, 2012, from http://www.acara.edu.au/verve/_resources/DRAFT_Shape_of_the_Australian_Curriculum-HPE-FINAL.pdf

Biddle, S. (1995). Exercise and psychosocial health. Research Quarterly for Exercise and Sport, 66(4), 292-297.

Board of Studies NSW. (2007). Board of Studies NSW Media Guide: The New Higher School Certificate and School Certificate 2001. Retrieved August 20, 2012, from http://www.boardofstudies.nsw.edu.au/bos_stats/hsc01_ mediaguide.html\#Presidentsmessage

Board of Studies NSW. (2011). Privacy management plan: the Privacy and Personal Information Protection Act. Retrieved from http://www.boardofstudies.nsw.edu.au/administration/privacy_plan.html

Board of Studies NSW. (2012). HSC examinations. Retrieved from http://www.boardofstudies.nsw.edu.au/hsc_exams/

Board of Studies NSW. (2012). Understanding HSC results. Retrieved from http://www.boardofstudies.nsw.edu.au/hsc-results/understanding.html

Bowen, W. G., \& Levin, S. A. (2003). Reclaiming the game: college sports and educational values. Princeton, NJ: Princeton University Press.

Cashman, R. (1995). Paradise of sport: the rise of organised sport in Australia. Oxford: Oxford University Press.

Coe, D. P., Pivarnik, J. M., Christopher, J., Womack, C. J., Reeves, M. J., \& Malina, R. M. (2006). Effect of Physical Education and Activity Levels on Academic Achievement in Children. The American College of Sports Medicine 38(8), 1515-1519.

Coleman, J. S. (1961). The Adolescent Society. New York: Free Press.

Collins, B., Aitken, M., \& Cork, B. (1990). One hundred years of public school sport in New South Wales 1889-1989. Sydney: New South Wales Department of School Education

Comeaux, E., \& Harrison, C. K. (2011). A conceptual model of academic success for student athletes. Educational Researcher, 40(5), 235-245.

Comeaux, E. (2005). Environmental predictors of academic achievement among student-athletes in the revenue-producing sports of men's basketball and football. The Sport Journal, 8(3), unpaginated.

Dollman, J., Boshoff, K., \& Dodd, G. (2006). The relationship between curriculum time for physical education and literacy and numeracy standards in South Australian primary schools. European Physical Education Review, 12(2), 151-163.

Dwyer, T., Coonan, W. E., Worsley, L. A., \& Leitch, D. R. (1979). An assessment of the effects of two physical activity programs on coronary heart disease risk factors in primary school children. Australian and New Zealand Journal of Public Health, 3(3), 196-202.

Eitzen, S. D. (2006). Fair and foul: beyond the myths and paradoxes of sport ( $3^{\text {rd }}$ ed.). Maryland, USA: The Rowman \& Littefield Publishing Group, Inc.

Ewing, R. (2010). The arts and Australian education: realising potential. Australian Education Review No. 58. Melbourne: ACER

Franks, M. (2011) Getting started: Working with Secondary Data. In K. Trzesniewski, B. Donnellan, \& R. Lucas (Eds), Secondary Data Analysis: An introduction for Psychologists. (pp.13-26). Washington: American Psychological Association. 
Gaston-Gayles, J. L., \& Hu, S. (2009). The influence of student engagement and sport participation on college outcomes among Division I student athletes. Journal of Higher Education, 80(3), 315-333.

Gaston-Gayles, J. L. (2005). The factors structure and reliability of the student athletes' motivation towards sports and academics questionnaire (SAMSAQ). Journal of College Student Development, 46(3), 317-327.

Gratton, C., \& Jones, I. (2004). Research methods for sports studies. Abingdon, Oxon: Routledge.

Hartmann, D. (2008). High school sports participation and educational attainment: recognizing, assessing, and utilizing the relationship. Minnesota: University of Minesota

Hauser, W. J., \& Lueptow, L. B. (1978). Participation in athletics and academic achievement: a replication and extension. Sociological Quarterly,19(2), 304-309.

http://www.audit.nsw.gov.au/ArticleDocuments/246/01_PAB_Physical_Activity_Full_Report.pdf.aspx?Embed=Y

Light, R. (2011). Accessing youth sport in Australia: schools and clubs. In S. Georgakis \& K. Russell (Eds), Youth Sport in Australia (pp. 59-70). Sydney: Sydney University Press.

Lindner, K. J. (2002). The physical activity participation-academic performance revisited: perceived and actual performance and the effect of banding (academic tracking). Pediatric Exercise Science, 14, 155-169.

Lipscombe, S. (2006). Secondary school extracurricular involvement and academic achievement: a fixed effects approach. Economics of Education Review, 26(4), 463-472.

Lueptow, L. B., \& Kayser, B. D. (1973). Athletic involvement, academic achievement and aspiration. Sociological Focus, 7(1), 24-36

MacMahon, J. R., \& Gross, R. T. (1987). Physical and psychological effects of aerobic exercise in boys with learning disabilities. Development and Behavioural Pediatrics, 8(5), 274-277.

Mahiri, J., \& Van, R. D. (2010). Out of bounds: when scholarship athletes become academic scholars. New York: Peter Lang.

Marsh, H. W. (1993). The effects of participation in sport during the last two years of high school. Sociology of Sport Journal, 10(1), 18-43.

Martin, K. (2010). Brain boost: sport and physical activity enhance children's learning. Retrieved from http://www.dsr.wa.gov.au/assets/files/Research/Brain\%20boost_emailer.pdf

Miller, K. E., Melnick, M. J., Barnes, G. M., Farrell, M. P., \& Sabo, D. (2005). Untangling the links among athletic involvement, gender, race, and adolescent academic outcomes. Social Sport Journal, 22(2), 178-193.

Miller, P. W., \& Voon, D. (2011). Lessons from My School. The Australian Economic Review, 44(4), 366-386.

NSW Office of Communities. (2010). Work and income of children: key statistics at a glance. Retrieved from http://picture.kids.nsw.gov.au/4/9/1/

NSW School Sport Unit (2011). NSW CHS Blues Souvenir Program. Sydney: NSW Board of Studies

Pfeifer, C., \& Cornelissen, T. (2010). The impact of participation in sports on educational attainment: new evidence from Germany. Economics of Education Review, 29(1), 91-103.

Pierce, C. E. (2007). An academic survey of engineering student athletes at a division I university. College Student Journal, 41(4), 801-812.

Polesel, J., Dulfer, N., \& Turnbull, M. (2012). The experience of education: the impacts of high stakes testing on school students and their families. Sydney: The Whitlam Institute, University of Western Sydney.

Sallis, J. F., McKenzie, T. L., Kolody, B., Lewis, M., Marshall, S., \& Rosengard, P. (1999). Effects of health-related physical education on academic achievement: Project Spark. Research Quarterly for Exercise and Sport, 70(2), $27-134$.

Shephard, R. J., \& Lavallee, H. (1994). Academic skills and required physical education: the Trois Rivieres experience. Recreation Research Supplements, 1(1), 1-12.

Silliker, S. A., \& Quirk, J. T. (1997). The effect of extracurricular activity participation on the academic performance of male and female high school students. The School Counsellor, 44(4), 288-293.

Simons, H. D., Bosworth, C., Fujita, S., \& Jensen, M. (2007). The athlete stigma in higher education. College Student Journal, 41(2), 251-273.

Tremblay, M., Inman, J., \& Willms, J. (2000). The relationship between physical activity, self-esteem, and academic 
achievement in 12-year-old children. Pediatric Exercise Science, 12(3), 312-324.

Trudeau, F., \& Shephard, R. J. (2008). Physical education, school physical activity, school sports and academic performance. International Journal of Behavioural Nutrition and Physical Activity 5(10), 1-12.

Trudeau, F., \& Shephard, R. J. (2010). Relationships of physical activity to brain health and the academic performance of schoolchildren. American Journal of Lifestyle Medicine, 4(2), 138-150.

Trzesniewski, K., Donnellan, B., \& Lucas, R. (2011). Secondary Data Analysis: An introduction for Psychologists. Washington: American Psychological Association.

Wilson, C. (2007). The Negative Impact of High-Stakes Testing on Students: A Literature Review. International Journal of Arts \& Sciences, 2(1), 8-11.

Wilson, C. (2012). Coates: compulsory sport a missing link in medal evolution. Sydney Morning Herald. Retrieved from

http://www.smh.com.au/olympics/news-london-2012/coates-compulsory-sport-a-missing-link-in-medal-evolution20120805-23o1v.html

\section{(c)) EY}

This work is licensed under a Creative Commons Attribution 3.0 License. 